\title{
Article
}

\section{"I'm So Tired": Fatigue as a Persistent Physical Symptom among Working People Experiencing Exhaustion Disorder}

\author{
Elín Broddadóttir ${ }^{1, *}$, Sigrún Ólafsdóttir Flóvenz ${ }^{1}$, Haukur Freyr Gylfason ${ }^{2}$, Pórey Pormar ${ }^{1}$, Hjalti Einarsson ${ }^{3}$, \\ Paul Salkovskis ${ }^{4}$ and Jón Friðrik Sigurðsson ${ }^{1,5}$
}

1 Department of Psychology, Reykjavik University, 102 Reykjavik, Iceland; sigrunola@ru.is (S.Ó.F.); thoreyt81@gmail.com (P.P.); jonfsig@ru.is (J.F.S.)

2 Department of Business, Reykjavik University, 102 Reykjavik, Iceland; haukurgy@ru.is

3 Stett.is, Icelandic Confederation of University Graduates, 105 Reykjavik, Iceland; hjalti@bhm.is

4 Oxford Centre for Psychological Health, Oxford Institute of Clinical Psychology Training and Oxford Cognitive Therapy Center, Warneford Hospital, Oxford University, Oxford OX3 7JX, UK; paul.salkovskis@hmc.ox.ac.uk

5 Faculty of Medicine, School of Health Sciences, University of Iceland, 102 Reykjavik, Iceland

* Correspondence: elinb@ru.is

\section{check for} updates

Citation: Broddadóttir, E.; Flóvenz, S.Ó.; Gylfason, H.F.; Pormar, P.;

Einarsson, H.; Salkovskis, P.;

Sigurðsson, J.F. “I'm So Tired":

Fatigue as a Persistent Physical Symptom among Working People Experiencing Exhaustion Disorder. Int. J. Environ. Res. Public Health 2021, 18, 8657. https://doi.org/10.3390/ ijerph18168657

Academic Editor: Paul B. Tchounwou

Received: 9 July 2021

Accepted: 14 August 2021

Published: 16 August 2021

Publisher's Note: MDPI stays neutral with regard to jurisdictional claims in published maps and institutional affiliations.

Copyright: (c) 2021 by the authors. Licensee MDPI, Basel, Switzerland. This article is an open access article distributed under the terms and conditions of the Creative Commons Attribution (CC BY) license (https:/ / creativecommons.org/licenses/by/ $4.0 /)$.

\begin{abstract}
Fatigue is widespread in the population, particularly among working people. Exhaustion disorder (ED), a clinical manifestation of burnout, is common, but, after treatment, about one-third still experience fatigue and other physical symptoms. We propose that in some instances, fatigue as a persistent physical symptom (PPS) might be a more appropriate formulation of ED patients' fatigue problems, and we suggest that ED patients who meet fatigue PPS criteria will differ from other ED patients in terms of psychological distress, non-fatigue PPSs and functional impairment. Questionnaires were sent to 10,956 members of a trade union of which 2479 (22.6\%) responded. Of 1090 participants who met criteria for ED, 106 (9.7\%) met criteria for fatigue as a PPS. Participants who met fatigue PPS criteria scored on average higher on measures of depression, anxiety and functional impairment and were more likely to have clinically significant scores. Moreover, they had 27 times higher odds of meeting other PPS subtypes and reported more non-fatigue PPS subtypes, suggesting a more complex health problem. Specific evidence-based interventions are available for both ED and PPSs, and therefore, it is crucial to accurately formulate the fatigue problem reported by patients to provide appropriate treatment.
\end{abstract}

Keywords: persistent physical symptoms; medically unexplained symptoms; exhaustion disorder; burnout; depression; anxiety; functional impairment; stress-related disorder

\section{Introduction}

Fatigue is widespread in the general population [1-3], frequently presented in primary care [4-6] and increasingly reported by the working population [7-9]. Fatigue in the workforce has attracted renewed attention, as it likely influences workers' motivation, performance, sick leave and disability [10] in addition to general mortality [11] with accompanying personal, organisational and societal costs [12,13]. The understanding of the pathophysiology and underlying mechanisms of fatigue is limited, but fatigue symptoms may indicate a wide variety of physical, neurological and psychological conditions [14]. For example, fatigue is a core symptom of several well-defined, unexplained conditions, common among working people, for which specific evidence-based interventions have been developed, including exhaustion disorder (ED), a clinical manifestation of burnout [15].

ED is a stress-related condition with fatigue as a central symptom, accompanied by other exhaustion-related symptoms. ED's diagnostic criteria were proposed by the Swedish National Board of Health and Welfare in 2003 as a clinical operationalisation of burnout [15-17]. The prevalence of ED in the working population ranges from 10 to 
$23 \%[10,18-23]$, and ED is associated with reduced work ability and sickness absences [24]. Individuals fulfil the diagnostic criteria for ED if they have experienced physical and mental symptoms of fatigue for at least 2 weeks and if the symptoms can be attributed to an identifiable stressor that has been present for at least 6 months. People must experience markedly reduced mental energy and at least four other symptoms of exhaustion, such as problems with concentration, sleep disturbances, irritability or physical symptoms [24].

$\mathrm{ED}$ and burnout interventions have both focused on the individual experiencing stress as well as the workplace environment and its stressors [25,26]. While evidence is inconclusive on workplace interventions, Cognitive Behavioural Therapy (CBT) and multimodal treatment for stress-related disorders, including ED, show promising results [26-29]. CBT and multimodal treatment seem to be effective in reducing psychological and stress-related physical symptoms but less effective when it comes to the number of sick leave days and returning to work [28,30-33]. Between 60 and $80 \%$ of ED patients do not meet criteria post-treatment $[31,34,35]$, and between 70 and $80 \%$ of ED patients return to work within a year regardless of intervention [36]. Despite these promising results, about one-third of ED patients continue to have disabling fatigue after being treated $[31,35,37,38]$ and about $20 \%$ continue to have multiple physical symptoms in addition to their fatigue [32]. This implies that around $5 \%$ of the workforce is still experiencing disabling fatigue after treatment. In light of this, we aim to explore the possibility that an alternative formulation of fatigue problems experienced by ED patients might in some instances be more appropriate, namely as a persistent physical symptom (PPS).

"PPS" is a new umbrella term used for physical symptoms that are persistent, distressing and have no known underlying biological cause. Many different terms have been used to describe such unexplained symptoms, including "medically unexplained symptoms" and "functional somatic symptoms". The latest versions of the Diagnostic and Statistical Manual of Mental disorders (DSM-5) [39] and the International Classification of Diseases (ICD11) [40] contain updated conceptualisations of somatic symptom disorder (DSM-5) and bodily distress disorder (ICD-11), which, although compatible with the definition of PPSs, no longer require the symptoms to be medically unexplained, and they can therefore be diagnosed alongside explained conditions. We use the term "PPS" as it encompasses strictly unexplained physical symptoms and is generally preferred by patients [41,42]. Several medically unexplained conditions with fatigue as the central or accompanying symptom fall under the umbrella term of PPSs, such as chronic fatigue syndrome, fibromyalgia, irritable bowel syndrome and non-cardiac chest pain. Some argue that PPSs are better defined as one condition rather than many, as it is common to meet criteria for multiple unexplained conditions, and there is considerable overlap in case definitions as well as non-symptom associations [43-47]. PPSs are divided into seven subtypes, which are, in addition to persistent fatigue, sleep difficulties, chronic pain, gastrointestinal problems, chest and heart conditions and gynaecological problems. In order to meet criteria for any PPS subtype, including persistent fatigue, the symptom must not be explained by any verifiable condition, disease or the influence of drugs or substances; the symptom must have been present for 6 months; and the symptom must significantly influence people's daily functioning.

PPSs are common in all health care settings [48-50] and are associated with high rates of disability [51-53], comorbid psychological disorders [54-58], unemployment [59,60] and work disability $[55,58,61,62]$. Additionally, PPS patients have a poor prognosis, especially when multiple symptoms are present [63], but studies show that CBT is an effective intervention for PPSs [64-67] and in particular persistent fatigue [68-70].

Little is known about the overlap between ED and PPSs. What we know comes from studies comparing burnout and chronic fatigue syndrome. Such comparison studies conclude that burnout and chronic fatigue syndrome overlap considerably but are nonetheless separate conditions [34,71-73]. Studies have found that burnout and chronic fatigue syndrome patients differ in terms of general health and perceived general health [72], causal attributions [71,72], emotional awareness capacity [74], health-related quality of life [73] 
and work absenteeism [34]. Further, people suffering from burnout have higher rates of recovery than patients with chronic fatigue syndrome [34].

In this study, we aimed to identify ED patients whose fatigue meets PPS criteria and explore whether they differ from other ED patients in terms of psychological distress, nonfatigue PPSs and functional impairment, inspecting whether this alternative formulation of the fatigue problem might be more appropriate. PPSs are associated with poor prognosis and complex psychophysiological problems, and we thus presume that the ED participants whose fatigue meets PPS criteria will be more depressed, anxious and functionally impaired and more likely to meet criteria for other PPS subtypes than participants whose fatigue does not meet PPS criteria.

\section{Materials and Methods}

\subsection{Participants and Procedures}

Participants were recruited from 13,000 members of the Icelandic Confederation of University Graduates (BHM), an umbrella organisation of 27 trade unions from public and private sectors. A survey was sent via email to 10,956 members from the BHM's main office email account with two reminders a week apart. Of the $2479(22.6 \%)$ who initially responded, $1898(76.6 \%)$ were women and $581(23.4 \%)$ men. However, in line with the aims of the study, the final sample consisted of $1090(44 \%)$ participants who met criteria for ED. Demographic characteristics of the participants are shown in Table 1. The study was approved by The National Bioethics Committee of Iceland (no. 18-044).

Table 1. Demographic characteristics of participants whose fatigue met or did not meet persistent physical symptom (PPS) criteria.

\begin{tabular}{|c|c|c|c|c|}
\hline Demographic Variables & All Participants & $\begin{array}{l}\text { Fatigue Met } \\
\text { PPS Criteria }\end{array}$ & $\begin{array}{l}\text { Fatigue Did Not Meet } \\
\text { PPS Criteria }\end{array}$ & $x^{2}$ \\
\hline \multicolumn{5}{|l|}{ Gender } \\
\hline Female & $892(81.8 \%)$ & $100(94.3 \%)$ & $792(80.5 \%)$ & \multirow[t]{2}{*}{$12.351^{* * *}$} \\
\hline Male & $198(18.2 \%)$ & $6(5.7 \%)$ & $192(19.5 \%)$ & \\
\hline \multicolumn{5}{|l|}{ Age } \\
\hline 30 years or younger & $60(5.5 \%)$ & $6(5.7 \%)$ & $54(5.5 \%)$ & \multirow[t]{3}{*}{0.006} \\
\hline $31-50$ years & $699(64.1 \%)$ & $68(64.2 \%)$ & $631(64.1 \%)$ & \\
\hline $51-70$ years & $331(30.4 \%)$ & $32(30.2 \%)$ & $299(30.4 \%)$ & \\
\hline \multicolumn{5}{|l|}{ Education completed } \\
\hline Undergraduate degree & $465(42.7 \%)$ & $52(49.1 \%)$ & $413(42.0 \%)$ & \multirow[t]{2}{*}{1.964} \\
\hline Graduate degree & $625(57.3 \%)$ & $54(50.9 \%)$ & $571(58.0 \%)$ & \\
\hline \multicolumn{5}{|l|}{ Marital status } \\
\hline Single & $128(11.8 \%)$ & $17(16.2 \%)$ & $111(11.4 \%)$ & \multirow[t]{3}{*}{2.971} \\
\hline Married/relationship & $880(81.4 \%)$ & $79(75.2 \%)$ & $801(82.1 \%)$ & \\
\hline Separated/widowed & $73(6.8 \%)$ & $9(8.6 \%)$ & $564(6.6 \%)$ & \\
\hline \multicolumn{5}{|l|}{ Employment } \\
\hline Executives and managers & $290(26.9 \%)$ & $32(30.8 \%)$ & $258(26.5 \%)$ & \multirow[t]{5}{*}{3.292} \\
\hline Specialists & $398(36.9 \%)$ & $32(30.8 \%)$ & $366(37.6 \%)$ & \\
\hline Specialists in human services & $335(31.1 \%)$ & $36(34.6 \%)$ & $299(30.7 \%)$ & \\
\hline Specialised workers & $9(0.8 \%)$ & $0(0.0 \%)$ & $9(0.9 \%)$ & \\
\hline Retail, service and other & $46(4.3 \%)$ & $4(3.8 \%)$ & $42(4.3 \%)$ & \\
\hline Total & $1090(100 \%)$ & $106(9.7 \%)$ & $984(90.3 \%)$ & \\
\hline
\end{tabular}

\subsection{Measures}

Demographic information. The survey included demographic questions on gender, age, marital status, education and employment (Table 1).

Self-rated Exhaustion Disorder (s-ED). The s-ED was used to assess whether participants met criteria for ED [24]. The instrument is a self-report checklist consisting of four items based on the diagnostic criteria for ED. Respondents are asked whether they have felt physically and/or mentally exhausted in the last two weeks; whether they believe the 
exhaustion to be caused by stress exposure over the last 6 months or more; and whether they have experienced any of the following symptoms in the last two weeks: concentration or memory problems, markedly reduced capacity to tolerate demands or to work under pressure, emotional instability or irritability, sleeping problems, physical weakness or being more easily fatigued and physical symptoms (such as muscular pain, chest pain, palpitations, gastrointestinal problems, vertigo or increased sensitivity to sound). Finally, respondents are asked whether these complaints have markedly decreased well-being and/or functional capacity. The answer options are 'Yes, to a great extent', 'Yes, somewhat' and 'No, not at all'. The criteria for ED are met if respondents experience exhaustion, can identify a stressor, experience at least four related symptoms and are functionally impaired. The s-ED has shown good construct validity $[17,22,24,75]$.

Persistent Physical Symptom Checklist (PPSC). PPSC was used to assess whether participants met criteria for persistent fatigue and other subtypes of PPSs [6]. It is a selfreport checklist used to identify people experiencing problems with seven subtypes of unexplained physical symptoms that interfere with functional capacity, i.e., sleep problems, pain, fatigue and muscle problems, gastrointestinal problems, problems with the heart and chest, dizziness or related problems and gynaecological problems. For each type of physical symptom, respondents are asked four questions: whether they have experienced the symptom for more than six months (except one month for sleep problems), whether their symptoms have a known cause and, if it is known, what it is. Finally, respondents are asked to indicate on a 9-point scale $(0=$ Not at all, $8=$ Very severely $)$ to what extent each problem interferes with their lives. The criteria for a particular PPS type are met if the problem has been present for more than six months, its cause is not known or the cause is an unexplained syndrome and the problem interferes with daily life, which is 4 or higher on the 9-point interference scale. Persistent fatigue as a PPS was assessed by asking whether respondents had experienced "excessive fatigue that is not alleviated by rest".

The Patient Health Questionnaire-9 (PHQ-9): Depressive symptoms were measured with PHQ-9 [76], a 9-item self-report instrument that measures severity of depression over the last two weeks (Cronbach's $\alpha=0.80$ ). Items are rated on a 4-point scale from 0 (not at all) to 3 (nearly every day) with total scores ranging from 0-27 points. A total score of 10 or more reliably differentiates between those who meet criteria for depression and those that do not [77].

The Generalized Anxiety Disorder-7 (GAD-7): The participants also completed GAD-7 (Cronbach's $\alpha=0.88$ ). GAD-7 is a 7-item self-report instrument that measures symptoms of general anxiety over the last two weeks [78]. Items are rated on a 4-point scale from 0 (never) to 3 (nearly every day), and total scores range from 0-21 points. A total score of 10 or more reliably differentiates between those who meet criteria for general anxiety disorder and those that do not [78].

The Work and Social Adjustment Scale (WSAS): Impaired functioning was assessed with the WSAS (Cronbach's $\alpha=0.87$ ) [79]. WSAS measures impaired functioning in five areas of everyday life: the ability to work, manage a home, form and maintain close relationships and engage in social and leisure activities. The scale consists of five items measured on a 9-point scale $(0=$ Not at all, $8=$ Very severely $)$ with a total score that ranges from 0 to 40 . Scores between 10 and 20 have been associated with significant functional impairment and scores over 20 a more severe pathology [79].

\subsection{Statistical Analysis}

Statistical analysis was carried out with SPSS 26 (IBM, Armonk, NY, USA). First, chi-square $\left(\chi^{2}\right)$ tests were used to determine whether the demographic characteristics of participants differed depending on meeting fatigue PPS criteria. Second, $t$-tests and chi-square tests were used to determine whether mean and clinically significant scores on PHQ-9, GAD-7 and WSAS differed between participants whose fatigue met PPS criteria and those that did not. Third, chi-square tests were used to estimate the odds of meeting criteria for any non-fatigue PPS subtypes between participants whose fatigue met PPS 
criteria and those that did not. Consequently, a binary logistic regression analysis estimated whether the number of reported non-fatigue PPSs predicted whether participants' fatigue met PPS criteria while controlling for symptoms of depression and general anxiety.

\section{Results}

\subsection{Demographic Characteristics}

Of the 1090 participants, who all met criteria for ED, 106 (9.7\%) experienced fatigue so persistent that it met PPS criteria (Table 1). Comparisons revealed that participants whose fatigue met PPS criteria were more likely to be women than participants whose fatigue did not meet PPS criteria. The groups did not significantly differ on other demographic variables $(p>0.05)$.

\subsection{Psychological Distress}

As can be seen in Table 2, participants whose fatigue met PPS criteria reported on average more symptoms of depression, anxiety and functional impairment than participants whose fatigue did not meet PPS criteria. There was a significant association between having fatigue that met PPS criteria and having symptoms of depression (PHQ-9), general anxiety (GAD-7) and functional impairment (WSAS) in the clinical range. Participants whose fatigue met PPS criteria were around two times more likely to have depression and anxiety symptoms in the clinical range and nine times more likely to have clinically significant functional impairment.

Table 2. Comparison of depressive symptoms, anxiety symptoms and functional impairment between participants whose fatigue met or did not meet PPS criteria.

\begin{tabular}{|c|c|c|c|c|c|}
\hline Measures & All Participants & $\begin{array}{l}\text { Fatigue Met } \\
\text { PPS Criteria }\end{array}$ & $\begin{array}{l}\text { Fatigue Did Not } \\
\text { Meet PPS Criteria }\end{array}$ & Sig. & Effect Size \\
\hline Means & $\mathrm{M}(\mathrm{SD})$ & $\mathrm{M}(\mathrm{SD})$ & $\mathrm{M}(\mathrm{SD})$ & $T$ & $r$ \\
\hline PHQ-9 & $9.34(4.6)$ & $11.63(5.0)$ & $9.08(4.5)$ & $-5.36^{* * *}$ & 0.17 \\
\hline GAD-7 & $7.73(4.6)$ & $9.49(5.1)$ & $7.52(4.5)$ & $-4.14^{* * *}$ & 0.13 \\
\hline WSAS & $13.04(8.4)$ & $20.07(8.6)$ & $12.22(8.0)$ & $-9.33^{* * *}$ & 0.28 \\
\hline Cut-offs & $N(\%)$ & $N(\%)$ & $N(\%)$ & $x^{2}$ & OR $[95 \% \mathrm{CI}]$ \\
\hline PHQ-9 $\geq 10$ & $389(35.7 \%)$ & $60(56.6 \%)$ & $392(33.4 \%)$ & $16.44^{* * *}$ & $2.43[1.6-3.8]$ \\
\hline GAD- $7 \geq 10$ & $290(26.6 \%)$ & $44(41.5 \%)$ & $246(25.0 \%)$ & $10.98^{* * *}$ & $2.04[1.3-3.1]$ \\
\hline WSAS $_{\geq 10}$ & $581(53.3 \%)$ & $91(85.8 \%)$ & $490(49.8 \%)$ & $44.37^{* * *}$ & 9.29 [4.3-20.3] \\
\hline
\end{tabular}

Note: ${ }^{* * *} p<0.001 \mathrm{M}=$ mean. $\mathrm{SD}=$ standard deviation. $\mathrm{OR}=$ odds ratio. $\mathrm{CI}=$ confidence interval.

\subsection{Number of Non-Fatigue PPSs}

Participants with fatigue as a PPS had 27 times higher odds $(95 \% \mathrm{CI}=16.4-45.2)$ of meeting criteria for any other PPS subtypes (79\%) compared to participants whose fatigue did not meet PPS criteria $(12 \%), \chi^{2}(1)=280.88, p<0.001$. Moreover, participants whose fatigue did not meet PPS criteria generally did not meet criteria for any PPS subtype $(88 \%)$, and the prevalence declines as the number of PPSs increase (Figure 1). Around $10 \%$ met criteria for one other subtype of PPSs, most commonly sleep problems and pain. However, among participants whose fatigue met PPS criteria, it was most common to meet criteria for one (40\%) or two (26\%) non-fatigue PPS subtypes, while $21 \%$ met criteria for fatigue as a PPS only. Pain and sleep problems are also the most common non-fatigue PPS criteria met among people whose fatigue met PPS criteria. A logistic regression analysis suggested that the number of reported non-fatigue PPSs significantly predicted whether fatigue PPS criteria were met while controlling for symptoms of depression and anxiety (data not shown). 


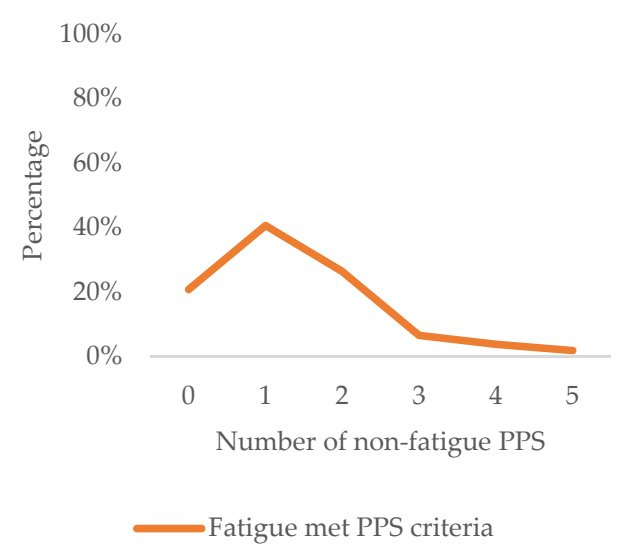

(a)

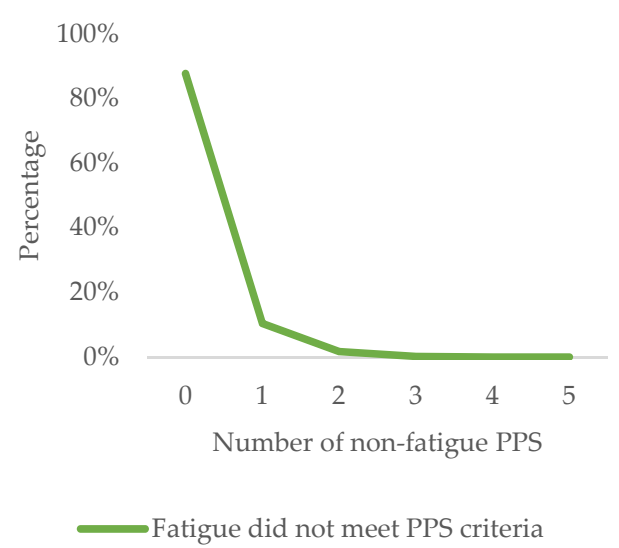

(b)

Figure 1. (a) Percentage of participants whose fatigue met PPS criteria and who met criteria for none, one or more non-fatigue PPS. (b) Percentage of participants whose fatigue did not meet PPS criteria and who met criteria for none, one or more non-fatigue PPS.

\section{Discussion}

Exhaustion disorder and persistent fatigue as a PPS have very similar symptomologies, as both have fatigue as the core symptom and are associated with sickness absence and work disability $[24,80]$. Despite this overlap, they are separate disorders with a differing prognosis $[34,72]$ and specialised interventions. We proposed that a portion of people who met ED criteria were experiencing fatigue that met criteria for PPS and that they would differ from other participants by experiencing more psychological distress and multiple PPSs. The results confirmed our conjecture, as participants whose fatigue met PPS criteria were more likely to have clinical levels of depression, anxiety and functional impairment, and a substantial proportion met criteria for multiple PPS subtypes.

Participants whose fatigue met PPS criteria scored on average higher on measures of depression, anxiety and functional impairment than their counterparts whose fatigue did not meet PPS criteria. Yet, the effect sizes were moderate. When using the measures' clinical cut-points, the results showed that participants whose fatigue met PPS criteria were twice as likely to have clinical levels of depressive and anxiety symptoms than participants whose fatigue did not meet PPS criteria and nine times more likely to have clinically significant functional impairment. Our results align with previous studies that indicate that $40-60 \%$ of PPS patients meet criteria for concurrent depressive and anxiety disorders $[6,52,56,81]$, but in our sample, $63 \%$ and $46 \%$ of participants with fatigue as a PPS had clinical levels of depression and general anxiety, respectively.

Participants whose fatigue met PPS criteria had 27 times higher odds of meeting any other PPS subtypes compared to participants without fatigue as a PPS, with $80 \%$ having two or more subtypes of PPSs, including persistent fatigue. Furthermore, depressive and anxiety symptoms did not predict whether participants' fatigue met PPS criteria, while the number of non-fatigue PPSs did. This corroborates the clinical importance of multiple PPSs. Previous research has shown that people with PPSs are a vulnerable group with poor functioning and a high chance of comorbidity with other PPSs and psychological disorders $[52,55,82,83]$, which suggests that the ED patients that meet criteria for fatigue as a PPS are likely suffering from a more complex problem and require different treatment.

We highlighted the very similar symptomologies of ED and persistent fatigue as a PPS. Fatigue that is not alleviated by rest is the primary symptom in both conditions and is often accompanied by sleep problems, concentration problems, pain and gastrointestinal problems among other symptoms $[6,15]$. The clearest differences in the diagnostic criteria are as follows: Firstly, symptoms in ED are stress related and are developed in response to an identifiable stressor. Although the literature indicates that post-traumatic stress 
and everyday stress may be precipitating, predisposing or perpetuating factors when it comes to PPSs [84] and fatigue-centred unexplained syndromes, such as chronic fatigue syndrome [73] and fibromyalgia [85-87], this association is contested and is not a requisite. Secondly, the timeframes of ED and fatigue as a PPS differ and might be a clinically important element when formulating the problem experienced by the patient and, hence, when providing treatment. Although ED has a long preface of stress, fatigue need only have been present for two weeks, and the onset is often sudden and intense [88]. On the other hand, fatigue as a PPS must be present for at least 6 months and is therefore long lasting, has a more chronic course and higher rates of reoccurrence [34]. Relatively little is known about the clinical course of ED [34,88], but studies suggest that symptom duration before intervention is highly important to recovery from ED [31] and fatigue in general [89].

There are several limitations to this study. Although the sample was large and consisted of working people only, it was non-random with self-selected participants. Additionally, the sample consisted of university educated employees only, and women were overrepresented. Further, our results are based on self-reporting of ED symptoms and PPSs; thus, it would be desirable to confirm our results with more robust methods, e.g., clinical interviews with standardised instruments and diagnostic evaluation of health care professionals. Furthermore, it would be of value to explore the association between ED, PPSs and diagnosed mental disorders to more effectively isolate associations with psychological distress and functional impairment by controlling for diagnosis and current treatment regimens.

Formulating the fatigue problem reported by patients accurately is crucial from a public health perspective as well as for providing appropriate treatment. Although the treatment interventions for ED and persistent fatigue as a PPS share some similarities, there are crucial differences. ED multimodal treatment is focused on stress reduction, which includes increasing physical activity and psychoeducation on lifestyle topics, insomnia and mental health CBT [31]. CBT for persistent fatigue as a PPS places focus on understanding the interrelation between mental and physical symptoms, psychoeducation and creating routines with activity pacing [90]. Our results suggest that among ED patients are people experiencing PPSs who might benefit from more specific PPS treatment. Previous studies indicate that at an 18 month follow-up after multimodal treatment, 33\% still meet criteria for ED [31] and $20 \%$ still experience six or more physical symptoms in addition to their fatigue [32]. In our sample, $10 \%$ of ED participants met criteria for fatigue as a PPS and $80 \%$ of those reported multiple PPSs. We thus speculate that for a substantial subgroup of ED patients, PPSs might be a more accurate formulation of their problems, as they are experiencing a more complex and persistent form of fatigue mixed with other physical symptoms that need specific intervention.

\section{Conclusions}

ED and fatigue as a PPS both have fatigue as a central symptom, both are often accompanied by other physical symptoms and both influence disability and work absenteeism [24,55,61]. Yet, they have a differing clinical course, prognosis and treatment $[34,88,90]$. Our results suggest that among ED patients, there might be a group of patients experiencing a more complex problem of multiple PPSs that warrants a specialised approach to treatment. With increasing societal and personal costs due to fatigue among the working population, it is crucial that clinicians and researchers continue to broaden the understanding and research of distinctive fatigue conditions, develop tools and resources to differentiate accurately between fatigue conditions and advance appropriate evidence-based treatment options.

Author Contributions: Conceptualisation, E.B., S.Ó.F., H.F.G., P.P., H.E. and J.F.S.; methodology, S.Ó.F., H.F.G., P.P., H.E., P.S. and J.F.S.; validation, S.Ó.F., H.F.G., P.S. and J.F.S.; formal analysis, E.B.; investigation, P.P., H.E.; data curation, E.B.; writing-original draft preparation, E.B.; writingreview and editing, S.Ó.F., H.F.G. and J.F.S.; visualisation, E.B.; supervision, P.S. and J.F.S. All authors have read and agreed to the published version of the manuscript. 
Funding: This research received no external funding.

Institutional Review Board Statement: The study was conducted according to the guidelines of the Declaration of Helsinki and approved by the National Bioethics Committee of Iceland (VSN-18-044, 20 February 2018).

Informed Consent Statement: Informed consent was obtained from all subjects involved in the study.

Data Availability Statement: The data presented in this study are available on request from the corresponding author. The data are not publicly available due to ethical restrictions.

Conflicts of Interest: The authors declare no conflict of interest.

\section{References}

1. Boter, H.; Mänty, M.; Hansen, A.M.; Hortobágyi, T.; Avlund, K. Self-Reported Fatigue and Physical Function in Late Mid-Life. J. Rehabil. Med. 2014, 46, 684-690. [CrossRef]

2. Engberg, I.; Segerstedt, J.; Waller, G.; Wennberg, P.; Eliasson, M. Fatigue in the General Population- Associations to Age, Sex, Socioeconomic Status, Physical Activity, Sitting Time and Self-Rated Health: The Northern Sweden MONICA Study 2014. BMC Public Health 2017, 17, 654-663. [CrossRef]

3. Hagelin, C.L.; Wengström, Y.; Runesdotter, S.; Fürst, C.J. The Psychometric Properties of the Swedish Multidimensional Fatigue Inventory MFI-20 in Four Different Populations. Acta Oncol. 2007, 46, 97-104. [CrossRef] [PubMed]

4. Cullen, W.; Kearney, Y.; Bury, G. Prevalence of Fatigue in General Practice. Ir. J. Med. Sci. 2002, 171, 10-12. [CrossRef]

5. Gallagher, A.M.; Thomas, J.M.; Hamilton, W.T.; White, P.D. Incidence of Fatigue Symptoms and Diagnoses Presenting in UK Primary Care from 1990 to 2001. J. R. Soc. Med. 2004, 97, 571-575. [CrossRef] [PubMed]

6. Flóvenz, S.Ó.; Broddadóttir, E.; Brynjólfsson, S.; Agnarsdóttir, A.S.; Salkovskis, P.M.; Sigurðsson, J.F. Prevalence of Persistent Physical Symptoms and Association with Depression, Anxiety and Health Anxiety in Iceland. Icel. Med. J. 2021, 107, 67-73. [CrossRef]

7. Rose, D.M.; Seidler, A.; Nübling, M.; Latza, U.; Brähler, E.; Klein, E.M.; Wiltink, J.; Michal, M.; Nickels, S.; Wild, P.S.; et al. Associations of Fatigue to Work-Related Stress, Mental and Physical Health in an Employed Community Sample. BMC Psychiatry 2017, 17, 167. [CrossRef] [PubMed]

8. Kant, I.; Bultmann, U.; Schroer, K.; Beurskens, A.; van Amelsvoort, L.G.P.M.; Swaen, G. An Epidemiological Approach to Study Fatigue in the Working Population: The Maastricht Cohort Study. Occup. Environ. Med. 2003, 60, i32-i39. [CrossRef] [PubMed]

9. Lee, S.; Seong, S.; Park, S.; Lim, J.; Hong, S.; Cho, Y.; Kim, H. Korean Version of the Swedish Occupational Fatigue Inventory among Construction Workers: Cultural Adaptation and Psychometric Evaluation. Int. J. Environ. Res. Public Health 2021, 18, 4302. [CrossRef] [PubMed]

10. Eurofound. Burnout in the Workplace: A Review of Data and Policy Responses in the EU; Publications Office of the European Union: Luxembourg, 2018.

11. Basu, N.; Yang, X.; Luben, R.N.; Whibley, D.; Macfarlane, G.J.; Wareham, N.J.; Khaw, K.-T.; Myint, P.K. Fatigue Is Associated with Excess Mortality in the General Population: Results from the EPIC-Norfolk Study. BMC Med. 2016, 14, 122. [CrossRef] [PubMed]

12. European Agency for Safety and Health at Work. Calculating the Costs of Work-Related Stress and Psychosocial Risks: Literature Review; Publications Office: Luxembourg, 2014.

13. Hassard, J.; Teoh, K.R.H.; Visockaite, G.; Dewe, P.; Cox, T. The Cost of Work-Related Stress to Society: A Systematic Review. J. Occup. Health Psychol. 2018, 23, 1-17. [CrossRef] [PubMed]

14. Nijrolder, I.; van der Windt, D.; de Vries, H.; van der Horst, H. Diagnoses during Follow-up of Patients Presenting with Fatigue in Primary Care. Can. Med. Assoc. J. CMAJ 2009, 181, 683-687. [CrossRef] [PubMed]

15. National Board of Health and Welfare. Exhaustion Disorder (Utmattningssyndrom-Stressrelaterad Psykisk Ohälsa); Socialstyrelsen: Stockholm, Sweden, 2003.

16. Maslach, C.; Schaufeli, W.B.; Leiter, M.P. Job Burnout. Annu. Rev. Psychol. 2001, 52, 397-422. [CrossRef] [PubMed]

17. Persson, R.; Österberg, K.; Viborg, N.; Jönsson, P.; Tenenbaum, A. Two Swedish Screening Instruments for Exhaustion Disorder: Cross-Sectional Associations with Burnout, Work Stress, Private Life Stress, and Personality Traits. Scand. J. Public Health 2017, 45, 381-388. [CrossRef] [PubMed]

18. Lindblom, K.M.; Linton, S.J.; Fedeli, C.; Bryngelsson, I.-L. Burnout in the Working Population: Relations to Psychosocial Work Factors. Int. J. Behav. Med. 2006, 13, 51-59. [CrossRef] [PubMed]

19. Lindert, J.; Müller-Nordhorn, J.; Soares, J.F. Age and Distress of Women-Results of a Representative Population-Based Study. Arch. Womens Ment. Health 2009, 12, 173-181. [CrossRef] [PubMed]

20. Norlund, S.; Reuterwall, C.; Höög, J.; Janlert, U.; Slunga Järvholm, L. Work Situation and Self-Perceived Economic Situation as Predictors of Change in Burnout-A Prospective General Population-Based Cohort Study. BMC Public Health 2015, 15, 329-338. [CrossRef] [PubMed]

21. Lexén, A.; Kåhlin, I.; Erlandsson, L.-K.; Håkansson, C. Occupational Health among Swedish Occupational Therapists: A Cross-Sectional Study. Int. J. Environ. Res. Public Health 2020, 17, 3379. [CrossRef] 
22. Asplund, S.; Åhlin, J.; Åström, S.; Hedlund, M.; Lindgren, B.-M.; Ericson-Lidman, E. Self-Rated Exhaustion Disorder and Associated Health-Related Factors among Municipal Employees in Rural Areas of Northern Sweden. Int. Arch. Occup. Environ. Health 2021, 94, 659-668. [CrossRef]

23. Persson, R.; Österberg, K. Repeated Assessment of Work-Related Exhaustion: The Temporal Stability of Ratings in the Lund University Checklist for Incipient Exhaustion. BMC Res. Notes 2020, 13, 304. [CrossRef]

24. Glise, K.; Hadzibajramovic, E.; Jonsdottir, I.H.; Ahlborg, G., Jr. Self-Reported Exhaustion: A Possible Indicator of Reduced Work Ability and Increased Risk of Sickness Absence among Human Service Workers. Int. Arch. Occup. Environ. Health 2010, 83, 511-520. [CrossRef]

25. Ahola, K.; Toppinen-Tanner, S.; Seppänen, J. Interventions to Alleviate Burnout Symptoms and to Support Return to Work among Employees with Burnout: Systematic Review and Meta-Analysis. Burn. Res. 2017, 4, 1-11. [CrossRef]

26. Wallensten, J.; Åsberg, M.; Wiklander, M.; Nager, A. Role of Rehabilitation in Chronic Stress-Induced Exhaustion Disorder: A Narrative Review. J. Rehabil. Med. 2019, 51, 331-342. [CrossRef] [PubMed]

27. Richardson, K.M.; Rothstein, H.R. Effects of Occupational Stress Management Intervention Programs: A Meta-Analysis. Database Abstr. Rev. Eff. DARE Qual. Assess. Rev. Internet 2008, 13, 69-93. [CrossRef] [PubMed]

28. Salomonsson, S.; Santoft, F.; Lindsäter, E.; Ejeby, K.; Ingvar, M.; Ljótsson, B.; Öst, L.-G.; Lekander, M.; Hedman-Lagerlöf, E. Effects of Cognitive Behavioural Therapy and Return-to-Work Intervention for Patients on Sick Leave Due to Stress-Related Disorders: Results from a Randomized Trial. Scand. J. Psychol. 2020, 61, 281-289. [CrossRef] [PubMed]

29. Lindsäter, E.; Axelsson, E.; Salomonsson, S.; Santoft, F.; Ejeby, K.; Ljótsson, B.; Åkerstedt, T.; Lekander, M.; Hedman-Lagerlöf, E. Internet-Based Cognitive Behavioral Therapy for Chronic Stress: A Randomized Controlled Trial. Psychother. Psychosom. 2018, 87, 296-305. [CrossRef]

30. Gavelin, H.M.; Boraxbekk, C.-J.; Stenlund, T.; Järvholm, L.S.; Neely, A.S. Effects of a Process-Based Cognitive Training Intervention for Patients with Stress-Related Exhaustion. Stress 2015, 18, 578-588. [CrossRef] [PubMed]

31. Glise, K.; Ahlborg, G.; Jonsdottir, I.H. Course of Mental Symptoms in Patients with Stress-Related Exhaustion: Does Sex or Age Make a Difference? BMC Psychiatry 2012, 12, 18-29. [CrossRef] [PubMed]

32. Glise, K.; Jonsdottir, I.H.; Ahlborg, G. Prevalence and Course of Somatic Symptoms in Patients with Stress-Related Exhaustion: Does Sex or Age Matter. BMC Psychiatry 2014, 14, 118. [CrossRef] [PubMed]

33. Grossi, G.; Santell, B. Quasi-Experimental Evaluation of a Stress Management Programme for Female County and Municipal Employees on Long-Term Sick Leave Due to Work-Related Psychological Complaints. J. Rehabil. Med. 2009, 41, 632-638. [CrossRef] [PubMed]

34. Leone, S.S.; Huibers, M.J.; Knottnerus, J.A.; Kant, Ij. A Comparison of the Course of Burnout and Prolonged Fatigue: A 4-Year Prospective Cohort Study. J. Psychosom. Res. 2008, 65, 31-38. [CrossRef]

35. Salomonsson, S.; Santoft, F.; Lindsäter, E.; Ejeby, K.; Ljótsson, B.; Öst, L.-G.; Ingvar, M.; Lekander, M.; Hedman-Lagerlöf, E. Cognitive-Behavioural Therapy and Return-to-Work Intervention for Patients on Sick Leave Due to Common Mental Disorders: A Randomised Controlled Trial. Occup. Environ. Med. 2017, 74, 905-912. [CrossRef]

36. Willert, M.V.; Thulstrup, A.M.; Bonde, J.P. Effects of a Stress Management Intervention on Absenteeism and Return to WorkResults from a Randomized Wait-List Controlled Trial. Scand. J. Work Environ. Health 2011, 37, 186-195. [CrossRef] [PubMed]

37. Glise, K.; Wiegner, L.; Jonsdottir, I.H. Long-Term Follow-up of Residual Symptoms in Patients Treated for Stress-Related Exhaustion. BMC Psychol. 2020, 8, 26-35. [CrossRef] [PubMed]

38. Lander, F.; Friche, C.; Tornemand, H.; Andersen, J.H.; Kirkeskov, L. Can We Enhance the Ability to Return to Work among Workers with Stress-Related Disorders? BMC Public Health 2009, 9, 372-376. [CrossRef] [PubMed]

39. American Psychiatric Association. Diagnostic and Statistical Manual of Mental Disorders: DSM-5, 5th ed.; American Psychiatric Association: Arlington, VA, USA, 2013.

40. World Health Organization. International Classification of Diseases for Mortality and Morbidity Statistics, 11th ed.; World Health Organization: Geneva, Switzerland, 2018.

41. Marks, E.M.; Hunter, M.S. Medically Unexplained Symptoms: An Acceptable Term? Br. J. Pain 2015, 9, 109-114. [CrossRef] [PubMed]

42. Picariello, F.; Ali, S.; Moss-Morris, R.; Chalder, T. The Most Popular Terms for Medically Unexplained Symptoms: The Views of CFS Patients. J. Psychosom. Res. 2015, 78, 420-426. [CrossRef]

43. Chalder, T.; Willis, C. "Lumping" and "Splitting" Medically Unexplained Symptoms: Is There a Role for a Transdiagnostic Approach? J. Ment. Health 2017, 26, 187-191. [CrossRef]

44. Dimsdale, J.; Sharma, N.; Sharpe, M. What Do Physicians Think of Somatoform Disorders? Psychosomatics 2011, 52, 154-159. [CrossRef] [PubMed]

45. Wessely, S.; Nimnuan, C.; Sharpe, M. Functional Somatic Syndromes: One or Many? Lancet 1999, 354, 936-939. [CrossRef]

46. Petersen, M.W.; Schröder, A.; Jørgensen, T.; Ørnbøl, E.; Dantoft, T.M.; Eliasen, M.; Thuesen, B.H.; Fink, P. The Unifying Diagnostic Construct of Bodily Distress Syndrome (BDS) Was Confirmed in the General Population Elsevier Enhanced Reader. J. Psychosom. Res. 2020, 128, 109868. [CrossRef]

47. Petersen, M.W.; Schröder, A.; Jørgensen, T.; Ørnbøl, E.; Meinertz Dantoft, T.; Eliasen, M.; Benros, M.E.; Fink, P. Irritable Bowel, Chronic Widespread Pain, Chronic Fatigue and Related Syndromes Are Prevalent and Highly Overlapping in the General Population: DanFunD. Sci. Rep. 2020, 10, 3273. [CrossRef] [PubMed] 
48. Nimnuan, C.; Hotopf, M.; Wessely, S. Medically Unexplained Symptoms: An Epidemiological Study in Seven Specialities. J. Psychosom. Res. 2001, 51, 361-367. [CrossRef]

49. Reid, S.; Wessely, S.; Crayford, T.; Hotopf, M. Medically Unexplained Symptoms in Frequent Attenders of Secondary Health Care: Retrospective Cohort Study. Br. Med. J. 2001, 322, 767. [CrossRef]

50. Roca, M.; Gili, M.; Garcia-Garcia, M.; Salva, J.; Vives, M.; Garcia Campayo, J.; Comas, A. Prevalence and Comorbidity of Common Mental Disorders in Primary Care. J. Affect. Disord. 2009, 119, 52-58. [CrossRef]

51. De Waal, M.W.M.; Arnold, I.A.; Eekhof, J.A.H.; van Hemert, A.M. Somatoform Disorders in General Practice-Prevalence, Functional Impairment and Comorbidity with Anxiety and Depressive Disorders. Br. J. Psychiatry 2004, 184, 470-476. [CrossRef] [PubMed]

52. Harris, A.; Orav, E.; Bates, D.; Barsky, A. Somatization Increases Disability Independent of Comorbidity. J. Gen. Intern. Med. 2009, 24, 155-161. [CrossRef] [PubMed]

53. Steinbrecher, N.; Koerber, S.; Frieser, D.; Hiller, W. The Prevalence of Medically Unexplained Symptoms in Primary Care. Psychosomatics 2011, 52, 263-271. [CrossRef] [PubMed]

54. Bekhuis, E.; Boschloo, L.; Rosmalen, J.G.M.; Schoevers, R.A. Differential Associations of Specific Depressive and Anxiety Disorders with Somatic Symptoms. J. Psychosom. Res. 2015, 78, 116-122. [CrossRef] [PubMed]

55. Den Boeft, M.; Twisk, J.W.R.; Hoekstra, T.; Terluin, B.; Penninx, B.W.J.H.; van der Wouden, J.C.; Numans, M.E.; van der Horst, H.E. Medically Unexplained Physical Symptoms and Work Functioning over 2 Years: Their Association and the Influence of Depressive and Anxiety Disorders and Job Characteristics.(Report). BMC Fam. Pract. 2016, 17, 46. [CrossRef] [PubMed]

56. Löwe, B.; Spitzer, R.L.; Williams, J.B.W.; Mussell, M.; Schellberg, D.; Kroenke, K. Depression, Anxiety and Somatization in Primary Care: Syndrome Overlap and Functional Impairment. Gen. Hosp. Psychiatry 2008, 30, 191-199. [CrossRef] [PubMed]

57. Budtz-Lilly, A.; Vestergaard, M.; Fink, P.; Carlsen, A.H.; Rosendal, M. Patient Characteristics and Frequency of Bodily Distress Syndrome in Primary Care: A Cross-Sectional Study. Br. J. Gen. Pract. 2015, 65, e617-e623. [CrossRef] [PubMed]

58. Park, J.; Gilmour, H. Medically Unexplained Physical Symptoms (MUPS) among Adults in Canada: Comorbidity, Health Care Use and Employment. Health Rep. 2017, 28, 3. [PubMed]

59. Aamland, A.; Malterud, K.; Werner, E.L. Patients with Persistent Medically Unexplained Physical Symptoms: A Descriptive Study from Norwegian General Practice. BMC Fam. Pract. 2014, 15, 107. [CrossRef] [PubMed]

60. Momsen, A.H.; Nielsen, C.V.; Nielsen, M.B.D.; Rugulies, R.; Jensen, C. Work Participation and Health-Related Characteristics of Sickness Absence Beneficiaries with Multiple Somatic Symptoms. Public Health 2016, 133, 75-82. [CrossRef]

61. Loengaard, K.; Bjorner, J.B.; Fink, P.K.; Burr, H.; Rugulies, R. Medically Unexplained Symptoms and the Risk of Loss of Labor Market Participation-a Prospective Study in the Danish Population. BMC Public Health 2015, 15, 844. [CrossRef] [PubMed]

62. Rask, M.T.; Ørnbøl, E.; Rosendal, M.; Fink, P. Long-Term Outcome of Bodily Distress Syndrome in Primary Care: A Follow-up Study on Health Care Costs, Work Disability, and Self-Rated Health. Psychosom. Med. 2017, 79, 345-357. [CrossRef]

63. Barsky, A.J.; Orav, E.J.; Bates, D.W. Somatization Increases Medical Utilization and Cost Independent of Psychiatric and Medical Comorbidity. Arch. Gen. Psychiatry 2005, 62, 903-910. [CrossRef] [PubMed]

64. Liu, J.; Gill, N.S.; Teodorczuk, A.; Li, Z.; Sun, J. The Efficacy of Cognitive Behavioural Therapy in Somatoform Disorders and Medically Unexplained Physical Symptoms: A Meta-Analysis of Randomized Controlled Trials. J. Affect. Disord. 2019, 245, 98-112. [CrossRef]

65. Sanders, S.; Coppin, S.; Moulson, H.; Meola, J.; Meyrick, J. What adaptions are effective to cognitive behavioural interventions for adults with long-term conditions and medically unexplained symptoms? A systematic review. Ansiedad Estrés 2020, 26, 188-201. [CrossRef]

66. Kleinstäuber, M.; Witthöft, M.; Hiller, W. Efficacy of Short-Term Psychotherapy for Multiple Medically Unexplained Physical Symptoms: A Meta-Analysis. Clin. Psychol. Rev. 2011, 31, 146-160. [CrossRef] [PubMed]

67. Kleinstäuber, M.; Allwang, C.; Bailer, J.; Berking, M.; Brünahl, C.; Erkic, M.; Gitzen, H.; Gollwitzer, M.; Gottschalk, J.-M.; Heider, J.; et al. Cognitive Behaviour Therapy Complemented with Emotion Regulation Training for Patients with Persistent Physical Symptoms: A Randomised Clinical Trial. Psychother. Psychosom. 2019, 88, 287-299. [CrossRef] [PubMed]

68. Kim, D.-Y.; Lee, J.-S.; Park, S.-Y.; Kim, S.-J.; Son, C.-G. Systematic Review of Randomized Controlled Trials for Chronic Fatigue Syndrome/Myalgic Encephalomyelitis (CFS/ME). J. Transl. Med. 2020, 18, 7. [CrossRef] [PubMed]

69. Malouff, J.M.; Thorsteinsson, E.B.; Rooke, S.E.; Bhullar, N.; Schutte, N.S. Efficacy of Cognitive Behavioral Therapy for Chronic Fatigue Syndrome: A Meta-Analysis. Clin. Psychol. Rev. 2008, 28, 736-745. [CrossRef] [PubMed]

70. White, P.; Goldsmith, K.; Johnson, A.; Potts, L.; Walwyn, R.; DeCesare, J.; Baber, H.; Burgess, M.; Clark, L.; Cox, D.; et al. Comparison of Adaptive Pacing Therapy, Cognitive Behaviour Therapy, Graded Exercise Therapy, and Specialist Medical Care for Chronic Fatigue Syndrome (PACE): A Randomised Trial. Lancet 2011, 377, 823-836. [CrossRef]

71. Huibers, M.J.H.; Beurskens, A.; Prins, J.B.; Kant, I.J.; Bazelmans, E.; Van Schayck, C.P.; Knottnerus, J.A.; Bleijenberg, G. Fatigue, Burnout, and Chronic Fatigue Syndrome among Employees on Sick Leave: Do Attributions Make the Difference? Occup. Environ. Med. 2003, 60, i26-i31. [CrossRef] [PubMed]

72. Leone, S.S.; Huibers, M.J.H.; Knottnerus, J.A.; Kant, I.J. Similarities, Overlap and Differences between Burnout and Prolonged Fatigue in the Working Population. QJM 2007, 100, 617-627. [CrossRef] [PubMed]

73. Maroti, D.; Bileviciute-Ljungar, I. Similarities and Differences between Health-Related Quality of Life in Patients with Exhaustion Syndrome and Chronic Fatigue Syndrome. Fatigue Biomed. Health Behav. 2018, 6, 208-219. [CrossRef] 
74. Maroti, D.; Molander, P.; Bileviciute-Ljungar, I. Differences in Alexithymia and Emotional Awareness in Exhaustion Syndrome and Chronic Fatigue Syndrome. Scand. J. Psychol. 2017, 58, 52-61. [CrossRef]

75. Wiegner, L.; Hange, D.; Björkelund, C.; Ahlborg, G. Prevalence of Perceived Stress and Associations to Symptoms of Exhaustion, Depression and Anxiety in a Working Age Population Seeking Primary Care-An Observational Study. BMC Fam. Pract. 2015, 16, 38-46. [CrossRef]

76. Kroenke, K.; Spitzer, R.L.; Williams, J.B. The PHQ-9: Validity of a Brief Depression Severity Measure. J. Gen. Intern. Med. 2001, 16, 606. [CrossRef] [PubMed]

77. Kroenke, K.; Spitzer, R.L.M.D. The PHQ-9: A New Depression Diagnostic and Severity Measure. Psychiatr. Ann. 2002, 32, 509-515. [CrossRef]

78. Spitzer, R.L.; Kroenke, K.; Williams, J.B.W.; Löwe, B. A Brief Measure for Assessing Generalized Anxiety Disorder: The GAD-7. Arch. Intern. Med. 2006, 166, 1092-1097. [CrossRef]

79. Mundt, J.; Marks, I.; Shear, M.; Greist, J. The Work and Social Adjustment Scale: A Simple Measure of Impairment in Functioning. Br. J. Psychiatry 2002, 180, 461-464. [CrossRef] [PubMed]

80. Leone, S.S.; Wessely, S.; Huibers, M.J.; Knottnerus, J.A.; Kant, Ij. Two Sides of the Same Coin? On the History and Phenomenology of Chronic Fatigue and Burnout. Psychol. Health 2011, 26, 449-464. [CrossRef]

81. Toft, T.; Fink, P.E.R.; Oernboel, E.V.A.; Christensen, K.A.J.; Frostholm, L.; Olesen, F. Mental Disorders in Primary Care: Prevalence and Co-Morbidity among Disorders. Results from the Functional Illness in Primary Care (FIP) Study. Psychol. Med. 2005, 35, 1175-1184. [CrossRef]

82. Flóvenz, S.Ó.; Salkovskis, P.M.; Svansdóttir, E.; Andersen, K. Non-Cardiac Chest Pain as a Persistent Physical Symptom and Its Relationship with Other Persistent Physical Symptoms, Psychological Distress and Workability. (submitted).

83. Rask, M.T.; Rosendal, M.; Fenger-Grøn, M.; Bro, F.; Ørnbøl, E.; Fink, P. Sick Leave and Work Disability in Primary Care Patients with Recent-Onset Multiple Medically Unexplained Symptoms and Persistent Somatoform Disorders: A 10-Year Follow-up of the FIP Study. Gen. Hosp. Psychiatry 2015, 37, 53-59. [CrossRef]

84. Mellner, C.; Krantz, G.; Lundberg, U. Medically Unexplained Symptoms in Women as Related to Physiological Stress Responses. Stress Health 2005, 21, 45-52. [CrossRef]

85. Conversano, C.; Carmassi, C.; Bertelloni, C.A.; Marchi, L.; Micheloni, T.; Carbone, M.G.; Pagni, G.; Tagliarini, C.; Massimetti, G.; Bazzichi, L. Potentially Traumatic Events, Post-Traumatic Stress Disorder and Post-Traumatic Stress Spectrum in Patients with Fibromyalgia. Clin. Exp. Rheumatol. 2019, 37, 39-43. [PubMed]

86. Fischer, S.; Doerr, J.M.; Strahler, J.; Mewes, R.; Thieme, K.; Nater, U.M. Stress Exacerbates Pain in the Everyday Lives of Women with Fibromyalgia Syndrome-The Role of Cortisol and Alpha-Amylase. Psychoneuroendocrinology 2016, 63, 68-77. [CrossRef] [PubMed]

87. Van Houdenhove, B.; Luyten, P. Stress, Depression and Fibromyalgia. Acta Neurol. Belg. 2006, 106, 149. [PubMed]

88. Grossi, G.; Perski, A.; Osika, W.; Savic, I. Stress-Related Exhaustion Disorder-Clinical Manifestation of Burnout? A Review of Assessment Methods, Sleep Impairments, Cognitive Disturbances, and Neuro-Biological and Physiological Changes in Clinical Burnout. Scand. J. Psychol. 2015, 56, 626-636. [CrossRef] [PubMed]

89. Ridsdale, L.; Evans, A.; Jerrett, W.; Mandalia, S.; Osler, K.; Vora, H. Patients with Fatigue in General Practice: A Prospective Study. Br. Med. J. 1993, 307, 103-106. [CrossRef] [PubMed]

90. Burgess, M.; Chalder, T. Overcoming Chronic Fatigue. A Self-Help Guide Using Cognitive Behavioural Techniques; Robinson: London, UK, 2009. 